\title{
Glutathione and proline can coordinately make plants withstand the joint attack of metal(loid) and salinity
}

\section{stresses}

\section{Naser A. Anjum ${ }^{1,2}$, Ibrahim M. Aref ${ }^{3}$, Armando C. Duarte ${ }^{2}$, Eduarda Pereira ${ }^{2}$, Iqbal Ahmad ${ }^{2}$ and Muhammad lqbal ${ }^{1 *}$}

'Department of Botany, Faculty of Science, Hamdard University, New Delhi, India

${ }^{2}$ CESAM-Centre for Environmental and Marine Studies and Department of Chemistry, University of Aveiro, Aveiro, Portugal

${ }^{3}$ Plant Production Department, College of Food and Agricultural Sciences, King Saud University, Riyadh, Saudi Arabia

${ }^{*}$ Correspondence: iqbalg5@yahoo.co.in

\section{Edited by:}

Dibyendu Talukdar, Raja Peary Mohan College (Affiliated to University of Calcutta), India

Reviewed by:

Dibyendu Talukdar, Raja Peary Mohan College (Affiliated to University of Calcutta), India

Yogesh Abrol, Bhagalpur University, India

Keywords: glutathione, metal/metalloids, osmotic stress, oxidative stress, proline, redox homeostasis, salinity stress

\section{INTRODUCTION}

Agricultural soils in the vicinity of extensive anthropogenic activities may exhibit salinity together with high levels of metals/metalloids (hereafter termed as "metal/s") as co-stressors. Elevated concentrations of metals (such as As, Cd, Cr, $\mathrm{Hg}, \mathrm{Ni}$, and $\mathrm{Pb}$ ) may affect photosynthetic apparatus, electron transport chain and chlorophyll biosynthesis, induce cellular damage, impair cellular redox homeostasis, and finally cause cellular metabolic arrest (Anjum et al., 2010, 2012a; Gill and Tuteja, 2010; Talukdar, 2012; Talukdar and Talukdar, 2014). Saline soil conditions, on the other hand, can cause osmotic stress that in turn can inhibit cell expansion and cell division, impact stomatal closure, induce cell turgor via lowering water potential, and alter the normal homeostasis of cells (Miller et al., 2010). However, the generation of osmotic stress through impaired plant water relations, and oxidative stress caused by uncontrolled generation of varied reactive oxygen species (ROS; such as such as - $\mathrm{OH}, \mathrm{H}_{2} \mathrm{O}_{2}, \mathrm{O}_{2}^{-}$) are common in plants exposed to high levels of salinity and/or metals (Benavides et al., 2005; Anjum et al., 2010, 2012a).

Diverse plant taxa have been reported to adapt metabolically to salinity and exposure to metals by enhancing synthesis of sulfur (S)-rich peptides (such as glutathione, GSH) and low-molecularweight nitrogenous and proteogenic amino acids/osmolytes (such as proline,
Pro) (Khan et al., 2009; Anjum et al., 2010, 2012a; Talukdar, 2012; Kishor and Sreenivasulu, 2014; Talukdar and Talukdar, 2014). Nevertheless, both GSH and Pro share L-glutamate as a common biosynthesis precursor (Moat et al., 2003) (Figure 1). However, very little or no effort has been made so far to dissect the intricacies of potential metabolic interrelationships between the GSH and Pro induction either under salinity/osmotic or metal stress conditions.

Therefore, we discuss and interpret through this note the facts related with the mainstays (chemistry, biosynthesis, compartmentalization, significance) commonly and potentially shared by these two enigmatic compounds (GSH and Pro) in plants. The outcome of the present endeavor can be useful in designing future research aimed at sustainably alleviating isolated and/or joint impact of metal and salinity stresses in crop plants through exploiting the GSH and Pro metabolism.

\section{CROSS-TALKS AND PERSPECTIVES}

Both GSH and Pro, with molecular formula $\mathrm{C}_{10} \mathrm{H}_{17} \mathrm{~N}_{3} \mathrm{O}_{6} \mathrm{~S}$ and $\mathrm{C}_{5} \mathrm{H}_{9} \mathrm{NO}_{2}$, respectively, belong to the "glutamate or $\alpha$-ketoglutarate" family and originate from a common precursor L-glutamate (Moat et al., 2003). Although cellular compartments and changing growth conditions may influence their levels, biosynthesis of both GSH (Preuss et al., 2014) and Pro (Lehmann et al., 2010) is predominantly plastidic. Of the two major GSH-biosynthesis enzymes, glutamate cysteine ligase (GCL; $\gamma$-glutamylcysteine synthetase; E.C. 6.3.2.2) is localized to plastid stroma; whereas GSH synthetase (GS; E.C. 6.3.2.3) is targeted to plastid stroma and cytosol (Ravilious and Jez, 2012). On the other hand, the Pro-biosynthesis enzymes, namely $\Delta 1$ pyrroline-5-carboxylate synthetase (P5CS) and $\Delta 1$-pyrroline-5-carboxylate reductase (P5CR), occur in cytosol and plastids (reviewed by Szabados and Savouré, 2010). Since plastids are among the major organelles with: (a) a highly oxidizing metabolic activity; (b) an intense rate of electron flow; and (c) plastid signal-mediated regulation of different cellular processes (Barajas-López et al., 2013), localization of both GSH and Pro is apt to their role as the major ROSscavenger and singlet-oxygen quencher during photosynthesis (Szekely et al., 2008).

GSH and Pro may occur in the concentrations of few $\mathrm{mM}(2-3 \mathrm{mM})$ in various plant tissues (Noctor et al., 2002; Kishor et al., 2005). The GSH and Pro levels of plant tissues are indicators of the S (reduced) (Hubberten et al., 2012) and nitrogen (N) (Sánchez et al., 2001) nutritional status of the plant respectively. GSH and Pro have also been reported to act as sources of (reduced)-S (Anjum et al., 2010) and N (reviewed by Kishor and Sreenivasulu, 2014), respectively, under 


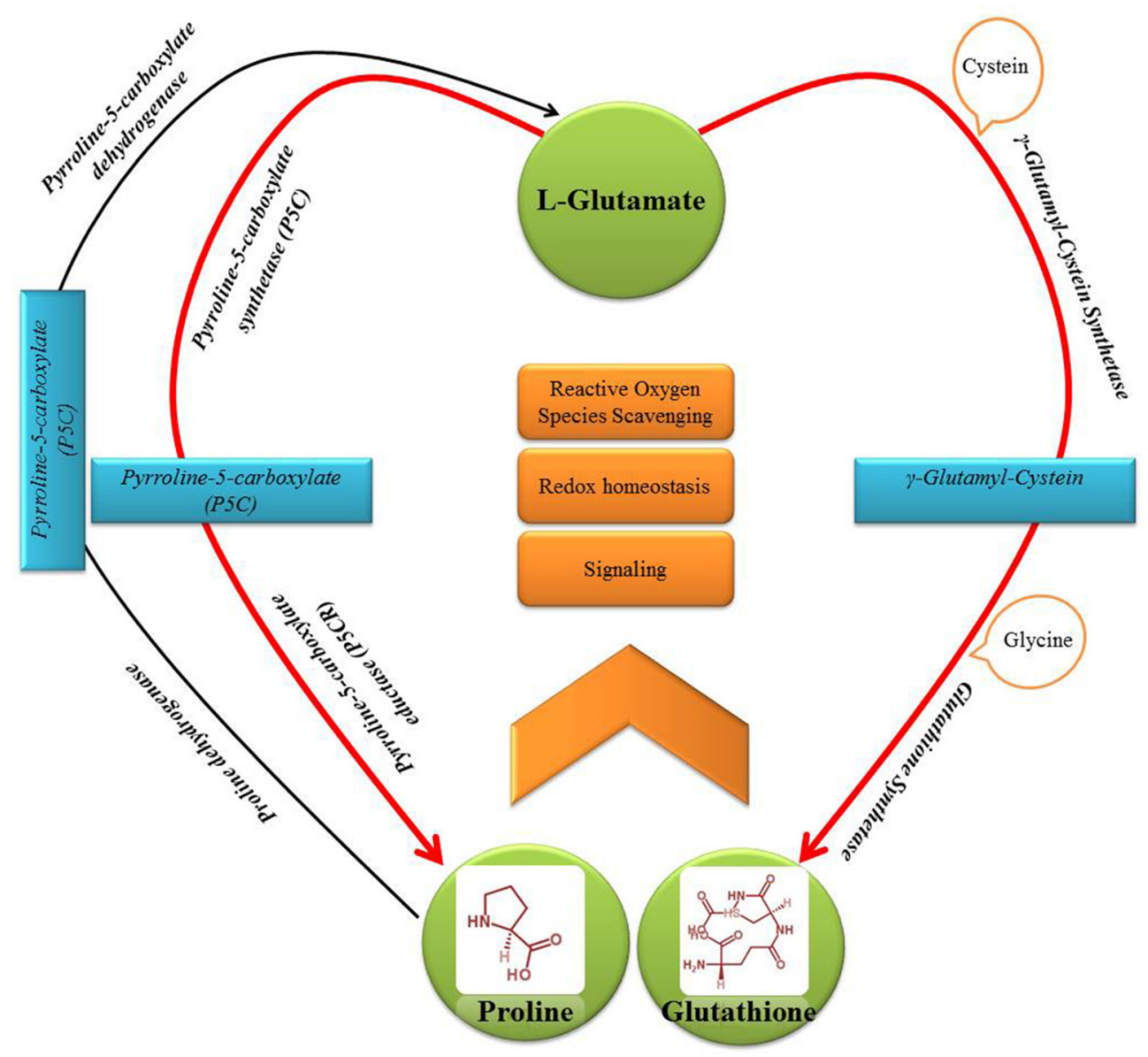

FIGURE 1 | Schematic representation of the points of interrelationships in the major metabolic pathway of sulfur-rich peptide-glutathione (GSH) and nitrogenous and proteogenic amino acid-proline (Pro).

stress conditions. Additionally, their status may presumably be improved through enhancing L-glutamate level via $\mathrm{N}$ and $S$ nutrition, respectively (Anjum et al., 2012b). Moreover, modulation of biosynthesis of GSH (Bartoli et al., 2009) and Pro (Abraham et al., 2003) is reportedly light dependent. In particular, GSH levels may depend on growth and photosynthetically active photon flux density at low light intensities (up to ca. $100 \mu \mathrm{mol} \mathrm{m} \mathrm{m}^{-2}$ $s^{-1}$ ) (Ogawa et al., 2004). GSH (Son et al., 2014) and Pro (Sivakumar et al., 2001) can negatively/positively modulate the photosynthesis functions by influencing the activity of ribulose-1,5-bisphosphate oxygenase, an enzyme involved in the first major step of carbon fixation. Moreover, an increased intracellular ROS-availability can shift the reduced GSH toward a more oxidized GSH (i.e., GSSG) status (Anjum et al., 2010, 2012a; Noctor et al., 2012). In contrast, increased status of cellular $\mathrm{H}_{2} \mathrm{O}_{2}$ (or exogenous $\mathrm{H}_{2} \mathrm{O}_{2}$ ) can increase Pro level by modulating the ex-novo synthesis of Pro (Matysik et al., 2002). Oxidation of Pro generates NADP/NADPH cycling or redox balance (Kishor et al., 2005) that in turn may regulate the reduction of GSSG to GSH via GSH reductase (Anjum et al., 2010, 2012a; Noctor et al., 2012). Interaction of Pro (Iqbal et al., 2014) and GSH (Mhamdi et al., 2010; Ghanta et al., 2014) with a number of defenserelated phytohormones (such as ethylene, jasmonic acid and salicylic acid) and/or their analogs has also been reported to modulate plant stress tolerance.

Both GSH (Ogawa, 2005) and Pro (Lehmann et al., 2010) perform multiple functions in plants including the modulation of plant growth and developmental processes. In particular, under metal stress, apart from the induction of GSH-based defense system (Anjum et al., 2010, 2012a; Noctor et al., 2012; Talukdar, 2012; Talukdar and Talukdar, 2014), elevated accumulation of osmolytes such as Pro has been extensively noticed (reviewed by Gill et al., 2014). Under salinity stress also, in addition to the accumulation of Pro that maintains both cell turgor and cellular redox homeostasis (Lehmann et al., 2010; Szabados and Savouré, 2010; Kishor and Sreenivasulu, 2014), GSH-based defense system is activated to maintain reduced cellular redox environment via metabolizing the varied ROS and their reaction products (Ruiz and Blumwald, 2002; Kocsy et al., 2004). Nevertheless, reports are available on the efficient Pro-metal, GSH-metal or ProGSH-metal sequestration, scavenging of 
ROS-types and also on the maintenance of reduced cellular redox environment by GSH (Anjum et al., 2010, 2012a; Noctor et al., 2012; Talukdar, 2012; Talukdar and Talukdar, 2014) and Pro (Matysik et al., 2002; Siripornadulsil et al., 2002; Lehmann et al., 2010; Szabados and Savouré, 2010; Kishor and Sreenivasulu, 2014).

A differential coordination of other components of ascorbate (AsA)-GSH pathway (enzymes such as ascorbate peroxidase, GSH reductase, GSH peroxidase, GSH sulfo-transferase, monodehydroascorbate reductase, dehydroascorbate reductase and catalase; and non-enzymes such as AsA) with GSH (Khan et al., 2009; Anjum et al., 2012a, 2014; Talukdar, 2012; Talukdar and Talukdar, 2014) and Pro (Omidi, 2010; Hossain et al., 2011; Anjum et al., 2014; Hasanuzzaman et al., 2014) was also reported to control plant tolerance to abiotic stress factors including the metal and salinity stress. Nevertheless, the status and responses of GSH and Pro together have been little explored in the same plant under similar stress conditions (Siripornadulsil et al., 2002; Hossain et al., 2011; Anjum et al., 2014; Hasanuzzaman et al., 2014). Notably, these studies helped to infer that there exists a close relation between GSH and Pro, and that exogenous and/or synthesized/ stress-caused elevated Pro can protect plants against the metal and salinity-stress impacts by safe-guarding the activity of previous enzymatic components, improving the cellular redox environment via decreasing $\mathrm{H}_{2} \mathrm{O}_{2}$ level and maintaining an increased level of reduced GSH and GSSG/GSH ratio.

Though an increased cellular GSH status is indicative of a plant's capacity to tolerate different stress pressures (Khan et al., 2009; Anjum et al., 2010, 2012a; Talukdar, 2012; Noctor et al., 2012; Talukdar and Talukdar, 2014), it is debatable whether accumulation of Pro is a plant response to abiotic stresses or it is associated with stress tolerance (Sorkheh et al., 2012; Kishor and Sreenivasulu, 2014). Also, elevated GSH is not always correlated with enhanced tolerance to stresses such as metals (Xiang et al., 2001; reviewed by Anjum et al., 2012a). Despite previous facts, as versatile redox buffers, Pro (Kishor and Sreenivasulu, 2014) and GSH (Anjum et al., 2010, 2012a; Noctor et al., 2012) have been extensively evidenced to protect cellular metabolism against a range of abiotic stresses.

The causal relationships of Pro accumulation and significance of GSH metabolism with enhanced tolerance to single stress factor (either metal or salinity) have been reported extensively in separate studies using natural variants, mutants or transgenic plants (Matysik et al., 2002; Anjum et al., 2010, 2012a; Noctor et al., 2012; Kishor and Sreenivasulu, 2014). However, significance of the potential "metabolic interrelationships" between GSH and Pro with reference to the plant's adaptive responses to prevailing multiple stressors has not been fully appreciated and the molecular insights of these relationships have yet to be developed.

Nevertheless, owing to the facts that: (a) deficiency of $\mathrm{S}$ and $\mathrm{N}$ has become extensive in agricultural soils on the globe (reviewed by Anjum et al., 2012b); (b) plant's $S$ requirement and $S$ metabolism are closely related to $\mathrm{N}$ nutrition, and the $\mathrm{N}$ metabolism is strongly affected by the plant's S status (Fazili et al., 2008; Anjum et al., 2012b); and (c) both GSH (Kopriva and Rennenberg, 2004; Anjum et al., 2012b) and Pro (Sánchez et al., 2001; Rais et al., 2013) are closely related to these nutrients, integrated efforts should be made to work-out the coordinated role of $\mathrm{S}$ and $\mathrm{N}$ in the GSH and Pro metabolic pathways, develop more insights into their biochemistry/physiology and molecular biology and understand potential interrelationships among different components of these pathways.

\section{ACKNOWLEDGMENTS}

Partial financial support received from Portuguese Foundation for Science and Technology (FCT) through post-doctoral research grants to NAA (SFRH/BPD/ 64690/2009; SFRH/BPD/84671/2012), and the Aveiro University Research Institute/Centre for Environmental and Marine Studies (CESAM) is gratefully acknowledged.

\section{REFERENCES}

Abraham, E., Rigo, G., Szekely, G., Nagy, R. Koncz, C., and Szabados, L. (2003). Lightdependent induction of proline biosynthesis by abscisic acid and salt stress is inhibited by brassinosteroid in Arabidopsis. Plant Mol.
Biol. 51, 363-372. doi: 10.1023/A:1022043 000516

Anjum, N. A., Ahmad, I., Mohmood, I., Pacheco, M., Duarte, A. C., Pereira, E., et al. (2012a). Modulation of glutathione and its related enzymes in plants' responses to toxic metals and metalloids-a review. Environ. Exp. Bot. 75, 307-324. doi: 10.1016/j.envexpbot.2011.07.002

Anjum, N. A., Gill, S. S., Umar, S., Ahmad, I., Duarte, A. C., and Pereira, E. (2012b). Improving growth and productivity of oleiferous Brassicas under changing environment: significance of nitrogen and sulphur nutrition, and underlying mechanisms. Sci. World J. 2012:657808. doi: 10.1100/2012/657808

Anjum, N. A., Israr, M., Duarte, A. C., Pereira, M. E., and Ahmad, I. (2014). Halimione portulacoides (L.) physiological/biochemical characterization for its adaptive responses to environmental mercury exposure. Environ. Res. 131, 39-49. doi: 10.1016/j.envres.2014.02.008

Anjum, N. A., Umar, S., and Chan, M. T. (2010). Ascorbate-Glutathione Pathway and Stress Tolerance in Plants. Dordrecht: Springer.

Barajas-López, J. D., Blanco, N. E., and Strand, $\AA$. (2013). Plastid-to-nucleus communication, signals controlling the running of the plant cell. Biochim. Biophys. Acta Mol. Cell Res. 1833, 425-437. doi: 10.1016/j.bbamcr.2012.06.020

Bartoli, C. G., Tambussi, E. A., Diego, F., and Foyer, C. H. (2009). Control of ascorbic acid synthesis and accumulation and glutathione by the incident light red/far red ratio in Phaseolus vulgaris leaves. FEBS Lett. 583, 118-122. doi: 10.1016/j.febslet.2008.11.034

Benavides, M. P., Gallego, S. M., and Tomaro, M. L. (2005). Cadmium toxicity in plants. Braz. J. Plant Physiol. 17, 21-34. doi: 10.1590/S167704202005000100003

Fazili, I. S., Jamal, A., Ahmad, S., Masoodi, M. Khan, J. S., and Abdin, M. Z. (2008). Interactive effect of sulfur and nitrogen on nitrogen accumulation and harvest in oilseed crops differing in nitrogen assimilation potential. J. Plant Nutr. 31, 1203-1220. doi: 10.1080/01904160802 134905

Ghanta, S., Datta, R., Bhattacharyya, D., Sinha, R., Kumar, D., Hazra, S., et al. (2014). Multistep involvement of glutathione with salicylic acid and ethylene to combat environmental stress. J. Plant Physiol. 171, 940-950. doi: 10.1016/j.jplph.2014. 03.002

Gill, S. S., Gill, R., and Anjum, N. A. (2014). "Target osmoprotectants for abiotic stress tolerance in crop plants - glycine betaine and proline," in Plant Adaptation to Environmental Change: Significance of Amino Acids and Their Derivatives, eds N. A. Anjum, S. S. Gill, and R. Gill (Wallingford, CT: CAB International), 97-108.

Gill, S. S., and Tuteja, N. (2010). Reactive oxygen species and antioxidant machinery in abiotic stress tolerance in crop plants. Plant Physiol. Biochem. 48, 909-930. doi: 10.1016/j.plaphy.2010.08.016

Hasanuzzaman, M., Alam, M. M., Rahman, A., Hasanuzzaman, M., Nahar, K., and Fujita, M. (2014). Exogenous proline and glycine betaine mediated upregulation of antioxidant defense and glyoxalase systems provides better protection against salt-induced oxidative stress in two 
rice (Oryza sativa L.) varieties. Biomed. Res. Intl. 2014:757219 doi: 10.1155/2014/757219

Hossain, M., Hasanuzzaman, M., and Fujita, M. (2011). Coordinate induction of antioxidant defense and glyoxalase system by exogenous proline and glycinebetaine is correlated with salt tolerance in mung bean. Front. Agric. China 5, 1-14. doi: 10.1007/s11703-010-1070-2

Hubberten, H. M., Drozd, A., Tran, B. V., Hesse, H., and Hoefgen, R. (2012). Local and systemic regulation of sulfur homeostasis in roots of Arabidopsis thaliana. Plant J. 72, 625-635. doi: 10.1111/j.1365313X.2012.05105.x

Iqbal, N., Umar, S., Khan, N. A., and Khan, M. I. R. (2014). A new perspective of phytohormones in salinity tolerance: regulation of proline metabolism. Environ. Exp. Bot. 100, 34-42. doi: 10.1016/j.envexpbot.2013.12.006

Khan, I., Ahmad, A., and Iqbal, M. (2009). Modulation of antioxidant defence system for arsenic detoxification in Indian mustard. Ecotoxicol. Environ. Saf. 72, 626-634. doi: 10. 1016/j.ecoenv.2007.11.016

Kishor, P. B. K., Sangam, S., Amrutha, R. N., Laxmi, P. S., Naidu, K. R., Rao, K. R. S. S., et al. (2005). Regulation of proline biosynthesis, degradation, uptake and transport in higher plants: its implications in plant growth and abiotic stress tolerance. Curr. Sci. 88, 424-438.

Kishor, P. B. K., and Sreenivasulu, N. (2014). Is proline accumulation per se correlated with stress tolerance or is proline homeostasis a more critical issue? Plant Cell Environ. 37, 300-311. doi: $10.1111 /$ pce. 12157

Kocsy, G., Szalai, G., and Galiba, G. (2004). Effect of osmotic stress on glutathione and hydroxymethylglutathione accumulation in wheat. J. Plant Physiol. 161, 785-794. doi: 10.1016/j.jplph.2003. 12.006

Kopriva, S., and Rennenberg, H. (2004). Control of sulphate assimilation and glutathione synthesis: interaction with $\mathrm{N}$ and $\mathrm{C}$ metabolism. J. Exp. Bot. 55, 1831-1842. doi: 10.1093/jxb/erh203

Lehmann, S., Funck, D., Szabados, L., and Rentsch, D. (2010). Proline metabolism and transport in plant development. Amino Acids 39, 949-962. doi: 10.1007/s00726-010-0525-3

Matysik, J., Alia, Bhalu, B., and Mohanty, P. (2002). Molecular mechanisms of quenching of reactive oxygen species by proline under stress in plants. Curr. Sci. 82, 525-532.

Mhamdi, A., Hager, J., Chaouch, S., Queval, G., Han, Y., Taconnat, L., et al. (2010). Arabidopsis GLUTATHIONE REDUCTASE 1 plays a crucial role in leaf responses to intracellular $\mathrm{H}_{2} \mathrm{O}_{2}$ and in ensuring appropriate gene expression through both salicylic acid and jasmonic acid signaling pathways. Plant Physiol. 153, 1144-1160. doi: 10.1104/pp.110.153767

Miller, G., Suzuki, N., Ciftci-Yilmaz, S., and Mittler, R. (2010). Reactive oxygen species homeostasis and signalling during drought and salinity stresses. Plant Cell Environ. 33, 453-467. doi: 10.1111/j.1365-3040.2009.02041.x

Moat, A. G., Foster, J. W., and Spector, M. P. (2003). "Biosynthesis and metabolism of amino acids," in
Microbial Physiology, eds A. G. Moat, J. W. Foster, and M. P. Spector (New York, NY: John Wiley \& Sons), 503-544.

Noctor, G., Gomez, L. A., Vanacker, H., and Foyer C. H. (2002). Interactions between biosynthesis, comparmentation and transport in the control of glutathione homeostasis and signaling. J. Exp. Bot. 53, 1283-1304. doi: 10.1093/jexbot/53. 372.1283

Noctor, G., Mhamdi, A., Chaouch, S., Han, Y. I., Neukermans, J., Marquez-Garcia, B. E. L. E. N., et al. (2012). Glutathione in plants: an integrated overview. Plant Cell Environ. 35, 454-484. doi: 10.1111/j.1365-3040.2011.02400.x

Ogawa, K. (2005). Glutathione-associated regulation of plant growth and stress responses. Antioxid. Redox Signal 7, 973-981. doi: 10.1089/ars.2005.7.973

Ogawa, K., Hatano-Iwasaki, A., Yanagida, M., and Iwabuchi, M. (2004). Level of glutathione is regulated by ATP-dependent ligation of glutamate and cysteine through photosynthesis in Arabidopsis thaliana: mechanism of strong interaction of light intensity with flowering. Plant Cell Physiol. 45, 1-8. doi: 10.1093/pcp/ pch008

Omidi, H. (2010). Changes of proline content and activity of antioxidative enzymes in two canola genotype under drought stress. Amer. J. Plant Physiol. 5, 338-349. doi: 10.3923/ajpp.2010.338. 349

Preuss, M. L., Cameron, J. C., Berg, R. H., and Jez, J. M. (2014). Immunolocalization of glutathione biosynthesis enzymes in Arabidopsis thaliana. Plant Physiol. Biochem. 75, 9-13. doi: 10.1016/j. plaphy.2013.11.027

Rais, L., Masood, A., Inam, A., and Khan, N. (2013). Sulfur and nitrogen co-ordinately improve photosynthetic efficiency, growth and proline accumulation in two cultivars of mustard under salt stress. J. Plant Biochem. Physiol. 1:101. doi: 10.4172/jpbp.1000101

Ravilious, G. E., and Jez, J. M. (2012). Stuctural biology of plant sulfur metabolism: from assimilation to biosynthesis. Nat. Prod. Rep. 29, 1138-1152. doi: $10.1039 / \mathrm{c} 2 \mathrm{np} 20009 \mathrm{k}$

Ruiz, J., and Blumwald, E. (2002). Salinityinduced glutathione synthesis in Brassica napus. Planta 214, 965-969. doi: 10.1007/s00425-0020748-y

Sánchez, E., López-Lefebre, L. R., García, P. C., Rivero, R. M., Ruiz, J. M., and Romero, L. (2001). Proline metabolism in response to highest nitrogen dosages in green bean plants (Phaseolus vulgaris L. cv. Strike). J. Plant Physiol. 158, 593-598. doi: 10.1078/0176-1617-00268

Siripornadulsil, S., Traina, S., Verma, D. P., and Sayre, R. T. (2002). Molecular mechanisms of prolinemediated tolerance to toxic heavy metals in transgenic microalgae. Plant Cell 14, 2837-2847. doi: 10.1105/tpc.004853

Sivakumar, P., Sharmila, P., and Saradhi, P. P. (2001). Proline suppresses rubisco activity by dissociating small subunits from holoenzyme. Biochem. Biophys. Res. Commun. 282, 236-241. doi: 10.1006/bbrc.2001.4540
Son, J. A., Narayanankutty, D. P., and Roh, K. S. (2014). Influence of exogenous application of glutathione on rubisco and rubisco activase in heavy metal-stressed tobacco plant grown in vitro. Saudi J. Biol. Sci. 21, 89-97. doi: 10.1016/j.sjbs.2013.06. 002

Sorkheh, K., Shiran, B., Khodambashi, M., Rouhi, V., Mosavei, S., and Sofo, A. (2012). Exogenous proline alleviates the effects of $\mathrm{H}_{2} \mathrm{O}_{2}$-induced oxidative stress in wild almond species. Russ. J. Plant Physiol. 59, 788-798. doi: 10. 1134/S1021443712060167

Szabados, L., and Savouré, A. (2010). Proline: a multifunctional amino acid. Trend Plant Sci. 15, 89-97. doi: 10.1016/j.tplants.2009.11.009

Szekely, G., Abraham, E., Cseplo, A., Rigo, G., Zsigmond, L., Csiszár, J., et al. (2008). Duplicated P5CS genes of Arabidopsis play distinct roles in stress regulation and developmental control of proline biosynthesis. Plant J. 53, 11-28. doi: 10.1111/j.1365-313X.2007. 03318.x

Talukdar, D. (2012). An induced glutathionedeficient mutant in grass pea (Lathyrus sativus L.): modifications in plant morphology, alteration in antioxidant activities and increased sensitivity to cadmium. Biorem. Biodiv. Bioavail. 6, 75-86.

Talukdar, D., and Talukdar, T. (2014). Coordinated response of sulfate transport, cysteine biosynthesis, and glutathione-mediated antioxidant defense in lentil (Lens culinaris Medik.) genotypes exposed to arsenic. Protoplasma 251, 839-855. doi: 10.1007/s00709-013-0586-8

Xiang, C., Werner, B. L., Christensen, E. M., and Oliver, D. J. (2001). The biological functions of glutathione revisited in Arabidopsis transgenic plants with altered glutathione levels. Plant Physiol. 126, 564-574. doi: 10.1104/pp.12 6.2 .564

Conflict of Interest Statement: The authors declare that the research was conducted in the absence of any commercial or financial relationships that could be construed as a potential conflict of interest.

Received: 26 September 2014; paper pending published: 03 October 2014; accepted: 06 November 2014; published online: 21 November 2014.

Citation: Anjum NA, Aref IM, Duarte AC, Pereira E, Ahmad I and Iqbal M (2014) Glutathione and proline can coordinately make plants withstand the joint attack of metal(loid) and salinity stresses. Front. Plant Sci. 5:662. doi: 10.3389/fpls.2014.00662

This article was submitted to Plant Physiology, a section of the journal Frontiers in Plant Science.

Copyright (C) 2014 Anjum, Aref, Duarte, Pereira, Ahmad and Iqbal. This is an open-access article distributed under the terms of the Creative Commons Attribution License (CC BY). The use, distribution or reproduction in other forums is permitted, provided the original author(s) or licensor are credited and that the original publication in this journal is cited, in accordance with accepted academic practice. No use, distribution or reproduction is permitted which does not comply with these terms. 